\title{
In Vitro Study on Biodegradation of Absorbable Suture Materials Used for Surgical Applications
}

\author{
IULIAN ANTONIAC ${ }^{1,2}$, AURORA ANTONIAC ${ }^{2 *}$, DANIELA GHEORGHITA ${ }^{2}$, \\ SEBASTIAN GRADINARU ${ }^{3}$ \\ ${ }^{1}$ Academy of Romanian Scientists, 3 Ilfov, 050044, Bucharest, Romania \\ ${ }^{2}$ University Politehnica of Bucharest, Faculty of Materials Science and Engineering, 313 Splaiul Independentei, 060042 \\ Bucharest, Romania \\ ${ }^{3}$ University of Medicine and Pharmacy Carol Davila Bucharest, Faculty of General Medicine, 8 Eroii Sanitari Str., 050474, \\ Bucharest, Romania
}

Abstract: The presented experimental research aims to compare the degradation degree of five different types of surgical sutures used in clinical practice and to discuss the influence of local $\mathrm{pH}$ on the degradation of a suture material. The surgical sutures were tested in terms of stability and hydrolytic biodegradation in Phosphate Buffer Saline $(P B S)$ solution varying the $\mathrm{pH}$ and the immersion time of the samples in the liquid medium. The surface properties, structural characteristics and the effects of hydrolytic biodegradation on the mechanical properties were studied using Fourier Transform Infrared Spectroscopy (FT-IR), Scanning Electron Microscopy (SEM), Degradation degree and Tensile Strength tests, respectively.

Keywords: surgical suture materials, hydrolytic degradation, tensile strength, SEM, FT-IR

\section{Introduction}

Synthetic polymeric biomaterials are currently used in a wide variety of medical applications, including surgery, raising concerns related to the $p \mathrm{H}$ dependent degradation of materials and the temporary or long-term contact of the polymeric materials with the tissues and biological substances.

In recent years, a large number of synthetic and natural polymers became available and the choice of a certain surgical suture material in surgery requires a complex appraisal, considering the wound healing particularities [1]. The study of the $p \mathrm{H}$ level influencing the retention of strength for these materials has been sparse so far.

A surgical suture is defined as a biomaterial device used for closing wounds. They are used on the internal tissues, organs, blood vessels and skin. In order to be used for medical application, surgical sutures should be biocompatible, flexible, sterile, and low-priced, should have sufficient mechanical strength and produce secure knots [2-4]. Among the physical and mechanical properties that must be known, we mention tensile strength, stiffness and suture size. Depending on the manufacturing process, surgical sutures can be classified into 3 groups: i) monofilament sutures, ii) multifilament sutures (braided or twisted) and iii) coated multifilament sutures [5-7]. The classification of the surgical sutures is shown in Figure 1.

The first two biodegradable polymers, extensively used for surgical sutures, were the polyesters, poly(lactic acid) (PLA) and poly(glycolic acid) (PGA) [8-10]. Nowadays, the common raw materials used for absorbable sutures are catgut, polylactide, polyglycolide, copolymers of polyglycolide and polylactide, while for nonabsorbable sutures the options include polymers as polyester, polypropylene, polyamide or silk $[11,12]$.

For synthetic polymers the most important way of degradation is the hydrolysis and the main factors influencing this process are: the type of chemical bond, crystallinity, water uptake, polymer/copolymer composition and medium $p \mathrm{H}$. The parameters that have been proposed to measure the degradation process are: polymers/copolymers molecular weight, loss of mechanical strength, monomer release and complete degradation into monomers.

\footnotetext{
*email: antoniac.aurora@gmail
} 
Understanding the mechanism of degradation is particularly important for the selection and design of materials in surgical applications, as this process can affect a number of events, as tissue regeneration, cell growth, immunological response and material biofunctionality [13-18].

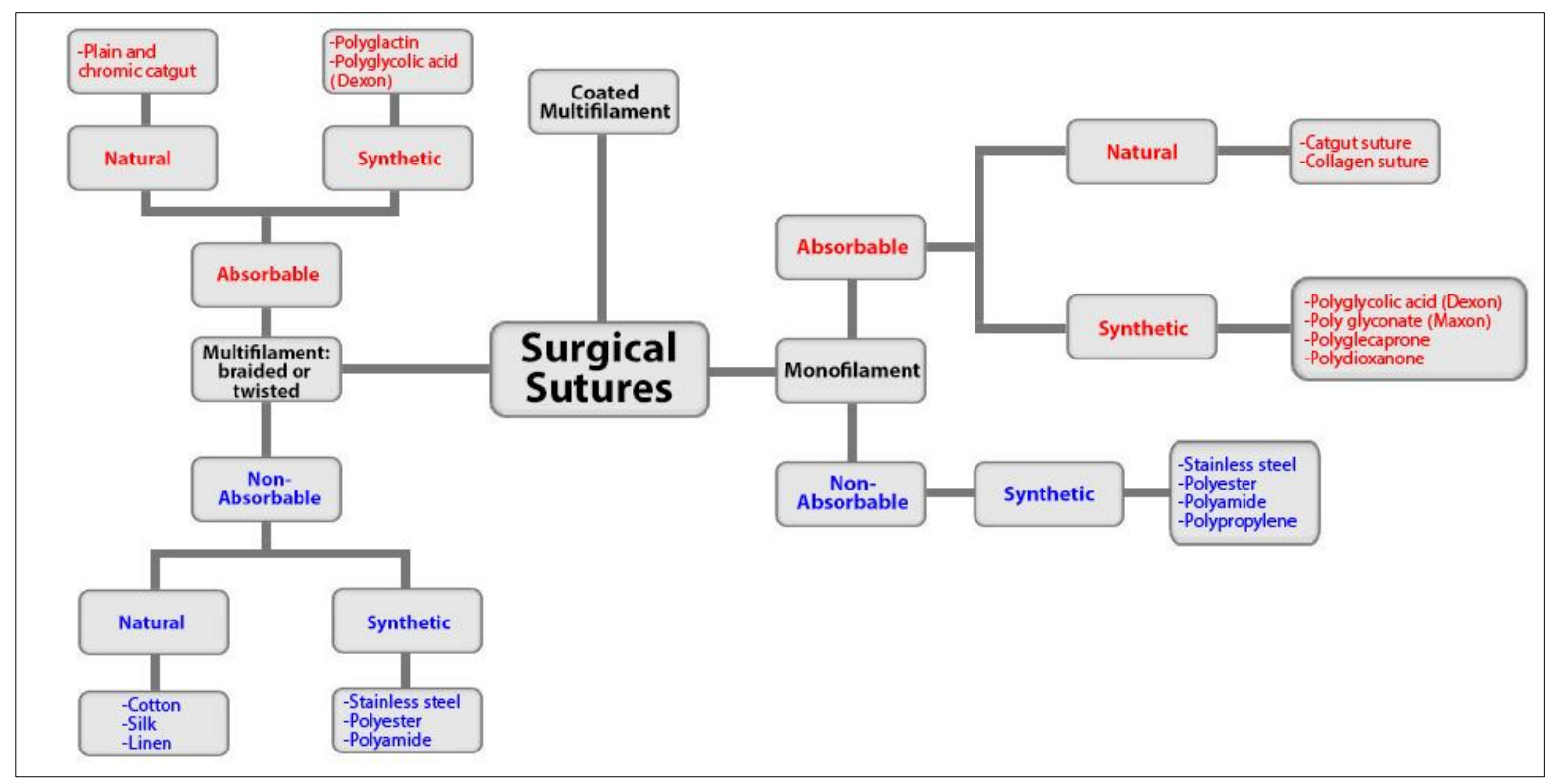

Figure 1. Surgical sutures classification

The most frequently used synthetic surgical sutures are glycolic acid copolymer with L-lactic acid (Vicryl), glycolic acid copolymer with $\varepsilon$-caprolactone (Monocryl), polidioxanone and non-absorbable polymers such as nylon, polyethylene, polypropylene (Prolene), polyester of polyvinylidene (PVDF).

In this study, different absorbable commercial surgical sutures were studied and tested in vitro to analyze their degradation and the effects of $p \mathrm{H}$ on the tensile properties.

\section{Materials and methods}

Five types of commercial absorbable surgical sutures were tested in terms of biodegradation in phosphate buffer solution (PBS) with two different $p \mathrm{H}$ values, respectively 4.4 and 7.4.

The value of $p \mathrm{H}$ is very important for biodegradation studies. It is known that in the human body the $p \mathrm{H}$ varies from $0.9-1.5$ corresponding to the $p \mathrm{H}$ of gastric juice in the stomach to 8.2 the $p \mathrm{H}$ of pancreatic juice in the duodenum; urinary $p \mathrm{H}$ often varies between 4.5 and 8.0 and physiological $p \mathrm{H}$ value of the skin surface ranging between 4.2-5.6 in healthy adults and children. According to this data, we select the $p \mathrm{H}$ value at 4.4 and 7.4 [19-21].

The coding of the experimental surgical suture samples is presented in Table 1.

Table 1. Experimental surgical suture coding

\begin{tabular}{|c|c|c|}
\hline Code & Surgical suture material & Suture type \\
\hline P1 & PDX - Polydioxanone & Absorbable, monofilament \\
\hline P2 & PLGA - Poly(lactic-co-glycolic acid) & Absorbable, multifilament braided \\
\hline P3 & Fast PGA - Polyglycolic acid & Absorbable, multifilament braided \\
\hline P4 & $\begin{array}{c}\text { PGA - Polyglycolic acid with a } \\
\text { higher molecular weight than sample P3 }\end{array}$ & Absorbable, multifilament braided \\
\hline P5 & PGC - Poly(glycolide-co- - -caprolactone) & Absorbable, monofilament \\
\hline
\end{tabular}

Fourier Transform Infrared Spectroscopy (FT-IR) was used to evaluate the structural characteristics of the polymers of which the surgical sutures are made of. The analysis was performed on a JASCO 6200 FT-IR spectrometer, equipped with a Golden Gate-type attenuated total reflection device (ATR). 
The spectra were recorded with a resolution of $4 \mathrm{~cm}^{-1}$, by overlapping about 160 spectra, which were later processed, using the dedicated software of the device.

The surface morphology of the investigated surgical sutures was evaluated using a Philips XL 30 ESEM Scanning Electron Microscope previous to in vitro biodegradation.

The investigated surgical sutures of $5 \mathrm{~cm}$ long were immersed in PBS solution, reproducing physiological conditions, with two different $p \mathrm{H}$ values, respectively 4.4 and 7.4. The $p \mathrm{H}$ was determined using a pH meter HI 2210 HANA instrument. The determinations were performed on the experimental samples in the initial state (control) and after immersion in the test medium for 2 weeks, 4 weeks, 6 weeks and 8 weeks.

The degradation degree of surgical sutures was evaluated by measuring the weight loss. The experimental samples were kept in the standard atmosphere for two hours before the initial weight measurement $\left(\mathrm{W}_{0}\right)$. They were then immersed in $25 \mathrm{~mL}$ PBS for previously established time $(2,4,6,8$ weeks), then removed from the solution, cleaned with deionized water, kept in the standard atmosphere until they reached constant weight and were weighed (W, weight after immersion). The percentage of degradation degree was calculated according to the formula:

$$
D D=\frac{W o-W}{W o} * 100
$$

The mechanical properties of the experimental samples were also evaluated, following their tensile strength. The investigated surgical sutures of $5 \mathrm{~cm}$ long were tested in triplicate. To measure the elongation of a sample at a constant speed and with an imposed load, we used GATAN MicroTest 2000N Module (Figure 2) with test speed of $0.4 \mathrm{~mm} / \mathrm{min}$, maximum elongation of $10 \mathrm{~mm}$ and distance between backs of $10 \mathrm{~mm}$.

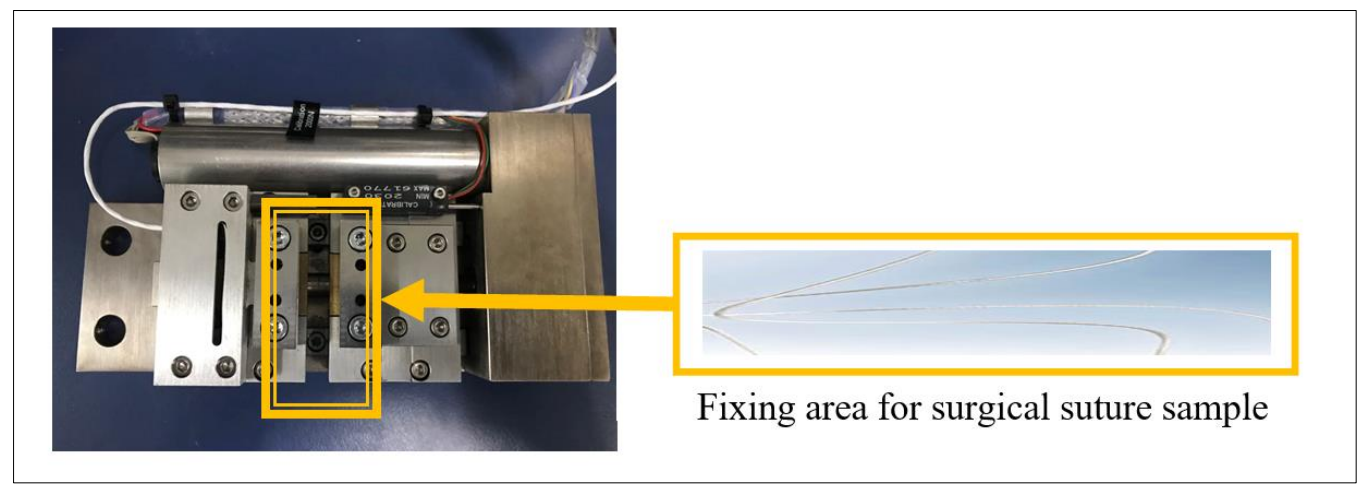

Figure 2. Fixation of the surgical suture sample for testing on GATAN MicroTest 2000N Module

\section{Results and discussions}

\subsection{Fourier-transform infrared spectroscopy results}

The chemical structure of polymers is important in assessing the degree of degradation both in-vivo and in-vitro degradation processes. The formation of the degradation products depends on the type of polymer, the degradation mechanism, and the type of additive present in the material. Fourier Transform Infrared Spectroscopy (FT-IR) was used in the study to evaluate the chemical structure of the polymers. The spectra were recorded by placing the dried samples directly on the crystal of the ATR device, and the results are presented in figure below. 


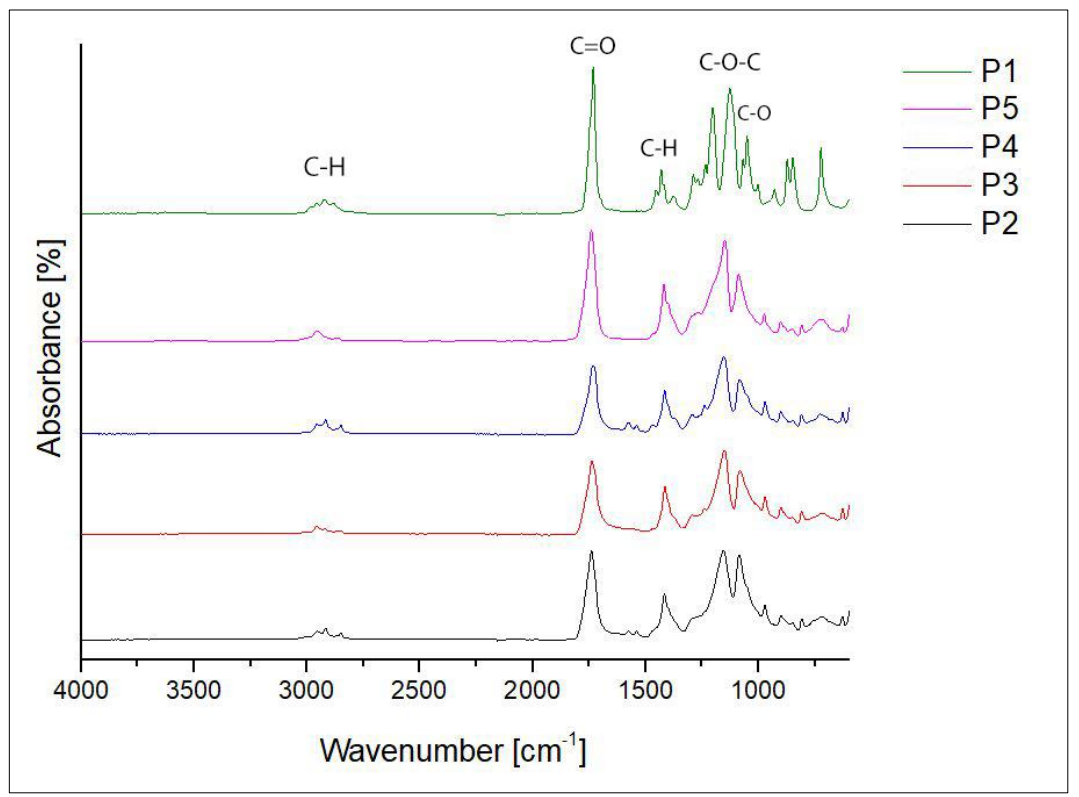

Figure 3. FT-IR spectra of the investigated surgical suture samples

Figure 3 shows the FT-IR spectra of the investigated surgical suture samples. In all spectra it can be observed a strong band between 1730 and $1740 \mathrm{~cm}^{-1}$ ascribed to the $\mathrm{C}=\mathrm{O}$ stretching vibration. There are also other characteristic absorption bands at around $1150 \mathrm{~cm}^{-1}\left(\mathrm{C}-\mathrm{O}-\mathrm{C}\right.$, ether) and $1085 \mathrm{~cm}^{-1}(\mathrm{C}-\mathrm{O}$, ester). C-H stretching bands were found between $2840 \mathrm{~cm}^{-1}$ and $3000 \mathrm{~cm}^{-1}$, while bending vibrations were observed at bands situated around $1415 \mathrm{~cm}^{-1}$. From $800-1200 \mathrm{~cm}^{-1}$ the absorption bands belong to C-C stretches.

The FT-IR measurements was made just to confirm that no biodegradation of the polymeric samples appear and to confirm that the polymeric surgical sutures are from polyester class, because the type of polymeric materials from which the surgical sutures are made was known from the details provided by manufacturer (polydioxanone, polyglycolic acid, lactic acid copolymer with glycolic acid, polyglycolic acid copolymer with caprolactone).

\subsection{Scanning electron microscopy results}

The surface of the experimental samples was analyzed in detail using Scanning Electron Microscopy (SEM).

SEM results obtained for each type of experimental sample are presented in the Figure 4. In the case of experimental sample P1 and P5, the surgical suture presents a monofilament homogeneous structure without microorganisms or debris, whereas samples P2, P3 and P4 present a multifilament surgical suture composed of several threads braided together. Braided surgical sutures show better tensile strength and more flexibility than monofilament surgical sutures, yet the latter present less tissue reaction and scar formation [19].

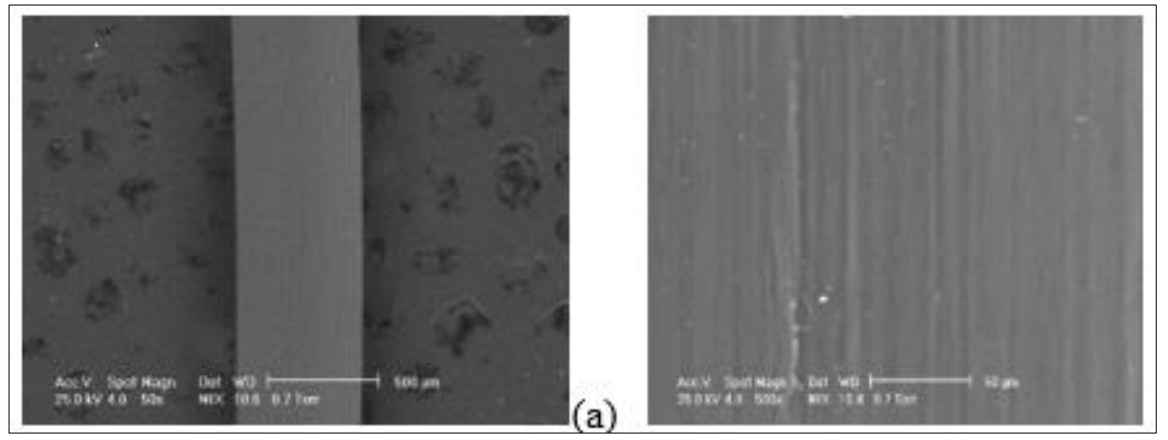



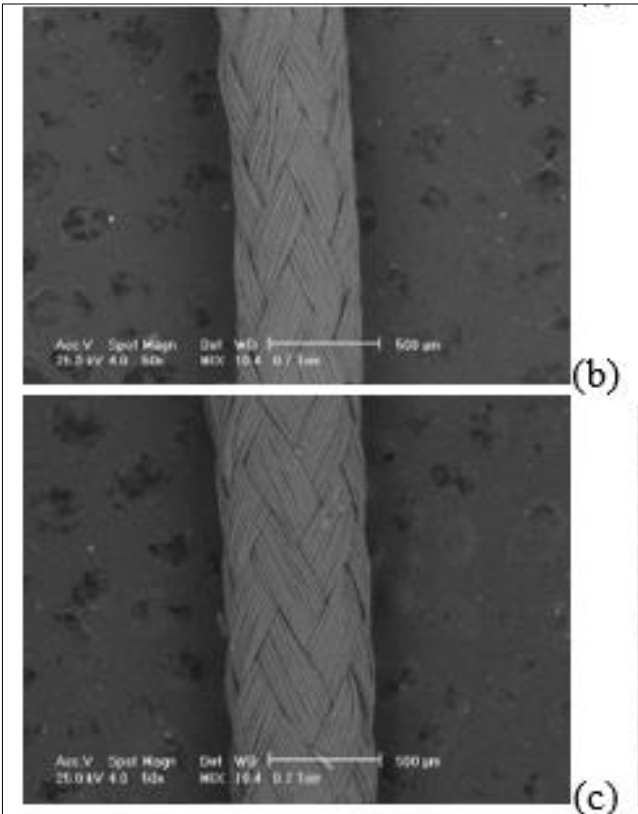

(b)

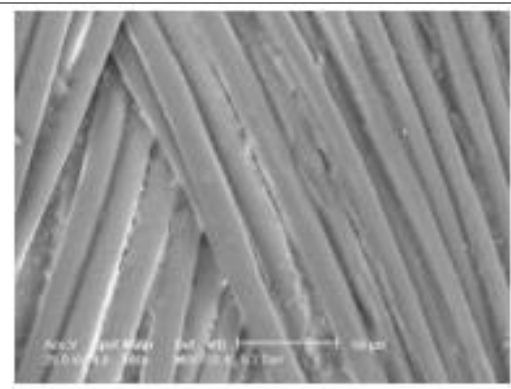

(c)
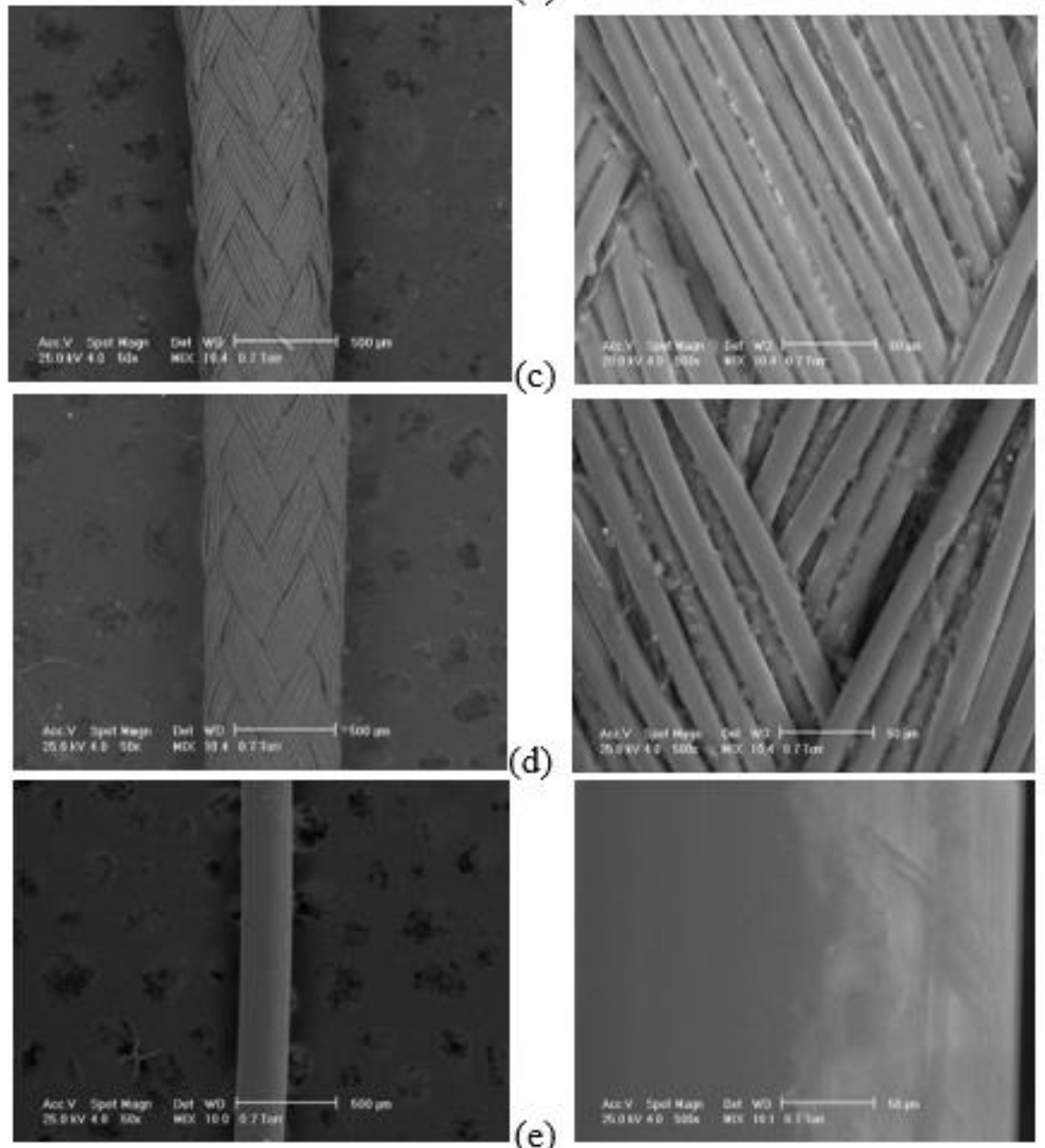

Figure 4. Scanning Electron Microscopy images of the investigated surgical suture samples: (a) P1 sample; (b) P2 sample; (c) P3 sample;

(d) P4 sample; (e) P5 sample

\subsection{Degradation of surgical sutures}

The degradation of the experimental samples from the surgical suture investigated during immersion in PBS is due to a hydrolysis process. The amount of water absorbed by the polymer is essential in the calculation of the degradation degree. Another important aspect is the molecular mass of the polymer, therefore, the lower the molecular mass of a polymer, the higher the degradation degree. Extrinsic factors that influence the degree of degradation include the presence of moisture, enzymes, $p \mathrm{H}$, temperature, microorganisms, stress applied to biomaterials and sterilization methods used.

The rate of hydrolytic reaction is affected by the surrounding $p \mathrm{H}$, so it is important to understand how the surgical sutures react to environments with different $p \mathrm{H}$ values. The evolution of the degradation degree by measuring the weight loss on the investigated experimental samples is presented in Figures 5 and 6. 

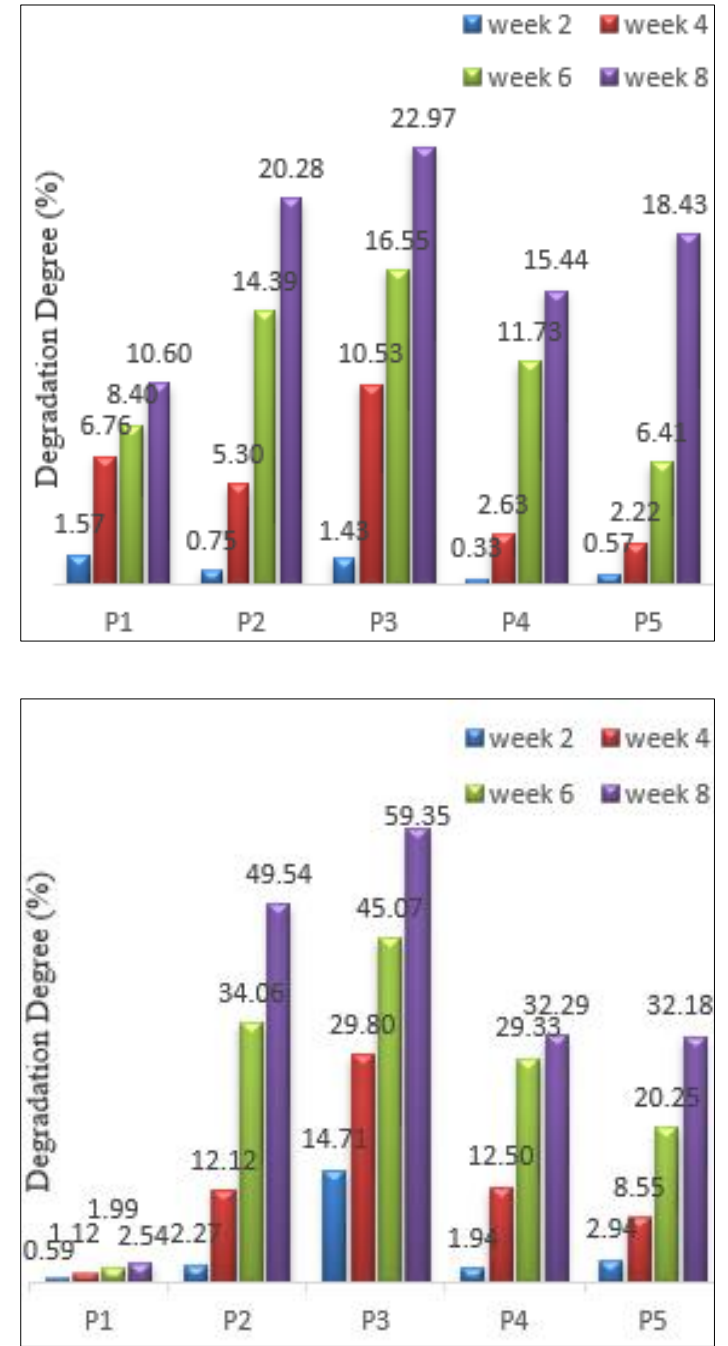

Figure 5. Evolution of the degradation degree of the samples investigated at $p \mathrm{H}=4.4(\mathrm{p}<0.05)$
Figure 6. Evolution of the degradation degree of the samples investigated at $p \mathrm{H}=7.4(\mathrm{p}<0.05)$

Based on Figures 5 and 6 we can observe that the degree of degradation, measured by weight loss, increases with the immersion time in the case of all the experimental samples investigated, regardless of the $p \mathrm{H}$ value (4.4 or 7.4) and the type of material [22-24]. Depending on the type of material, it is observed that sample P1, made from polydioxanone, a polymer with a weak hydrophilic character, has the lowest degree of degradation, while the highest degree of degradation is observed in the case of the sample P3 made from polyglycolic acid with low molecular mass and strongly hydrophilic. In the case of samples P3 and P4, both made of polyglycolic acid, a difference between the values of the degradation degree is observed due to the fact that the molecular mass of sample P3 is lower. Furthermore, depending on the $p \mathrm{H}$ value, it is observed that at $p \mathrm{H}=7.4$ the samples degrade faster than under acidic conditions. Also, an important aspect was highlighted in the case of samples P2 (Poly(lactic-co-glycolic acid)) and P5 (Poly(glycolide-co- $\varepsilon$-caprolactone)). Although polylactic acid is degraded in 2-5 years, respectively polycaprolactone in a period of more than 2 years, the copolymerization with glycolic acid increases considerably the degradation degree. This is explained by the fact that in the case of the formed copolymer containing both components, strongly hydrophilic and weakly hydrophilic, the degradation degree is higher than that of the homopolymer. Although a general increase in the degree of degradation is observed in the samples tested under alkaline conditions, sample P1 (polydioxanone) shows a strong slowdown of the degradation process.

Based on the local $p \mathrm{H}$, absorbable surgical sutures are recommended for tissues containing acidic fluids, in gastro-intestinal, urologic, and biliary tract surgery [20]. The acidic milieu counteracts microbial colonization, and it also favours healing in a complex way, inclusively by an increase in the amount of available oxygen for cells due to the Bohr-effect [25]. It is the case of the skin surface, where 
the physiological $p \mathrm{H}$ value, ranging between 4.2-5.6 in healthy adults and children, allows a normal degradation process of the surgical sutures of the wounds. An increased $p \mathrm{H}$ builds a favourable medium for bacteria, and thus for infection. A wound infection can present a $p \mathrm{H}$ up to 10.0, in which case the surgical sutures will degrade twice as fast, leading to wound dehiscence [26]. In the case of contaminated wounds, absorbable braided suture should not be used, but modern evaluation techniques suggest that bacterial adherence dependents not only on the braid itself, but also the absorbency of the material [27].

\subsection{Tensile testing of sutures}

The strength of a surgical suture material is important for several reasons, including the ability of the suture threads to withstand knotting and stress when used to bring the soft tissues into apposition. Low resistance surgical sutures tend to break during surgery or, more importantly, post-surgery. The tension corresponding to the maximum force required by the surgical suture prior to its breaking is called tensile strength, which is a conventional feature of the material being tested. The tensile strength of the surgical suture increases with diameter (the diameter of the surgical suture that can be expressed by a code number of one of two different standard rules, United States Pharmacopoeia and European Pharmacopoeia). The results obtained on initial (control) surgical suture and after immersion in PBS at 4 and 6 weeks are shown in the following figures (Figure 7 and Figure 8).

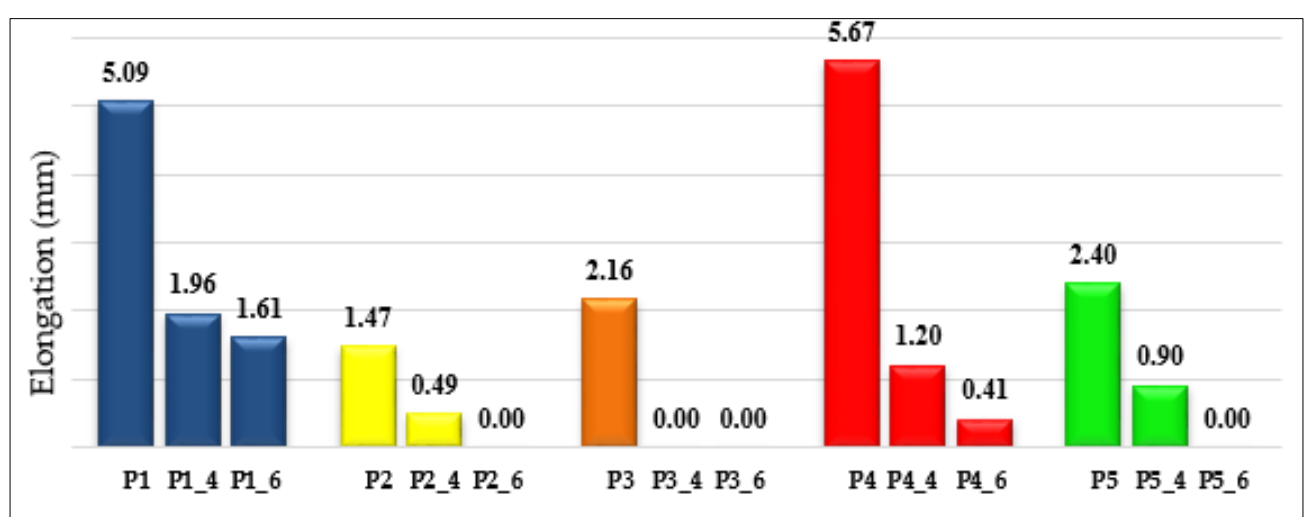

Figure 7. Variation of elongation after tensile testing of the initial experimental samples, immersed in PBS, 4 weeks (P1_4, P2_4, P3_4, P4_4, P5_4) and 6 weeks (P1_6, P2_6, P3_6, P4_6, P5_6) at $p \mathrm{H} 4.4$

Regardless of the $p \mathrm{H}$ of the test medium, it is observed that the elongation decreases with increasing immersion time. In the case of polyglycolic acid surgical suture at 4 and 6 weeks, respectively of the poly(lactic-co-glycolic acid) at 6 weeks, the elongation value is zero (these strands were broken during the degradation process). The best behaviour recorded after tensile strength tests was observed for the P1 sample made of polydioxanone for which the elongation value recorded at 6 weeks of immersion is $1.589 \mathrm{~mm}($ at $p \mathrm{H} \mathrm{7.4)}$ and $1.609 \mathrm{~mm}$ respectively at $p \mathrm{H}$ of 4.4. These results are in agreement with the results obtained when determining the degree of degradation and at the same time PDX is the only surgical suture that has retained its integrity after 8 weeks of immersion in the PBS solution.

In the case of surgical sutures made of polyglycolic acid (sample P3 and P4) but of different diameters, a better behaviour is observed for sample P4 although the thread diameter is smaller. This is due to the fact that the molecular weight of the polyglycolic acid from which the P4 sample is made is higher, which means better degradation behaviour and thus a higher tensile strength.

In the case of surgical sutures made of polyglycolic acid (sample P3 and P4) but of different diameters, a better behaviour is observed for sample P4 although the thread diameter is smaller. This is due to the fact that the molecular weight of the polyglycolic acid from which the P4 sample is made is higher, which means better degradation behaviour and thus a higher tensile strength.

The mechanical properties of the clinically used surgical sutures are correlated with the degree of degradation of the polymers, but also with the clinical necessity and different surgical procedures. 


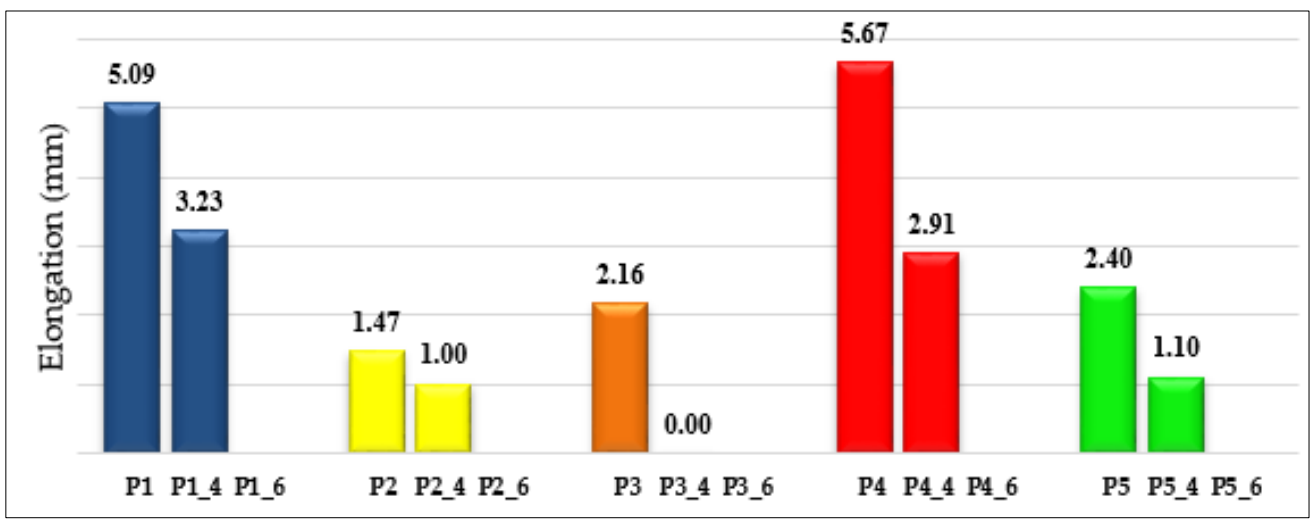

Figure 8. Variation of elongation after tensile testing of the initial experimental samples, immersed in PBS, 4 weeks (P1_4, P2_4, P3_4, P4_4, P5_4) and 6 weeks (P1_6, P2_6, P3_6, P4_6, P5_6) at $p \mathrm{H}$ 7.4.

Tensile strength of the suture is required in areas of higher tension or mechanical stress such as closure of the abdominal wall. The trials in this field usually evaluate early wound failure caused by wound infection and dehiscence or late wound failures (incisional hernia, sinus and fistula formation). Some studies found that elective midline laparotomy has a significant lower chance of incisional hernia if a slowly absorbable (vs. rapidly absorbable) suture material is used with a continuous technique, but for emergency interventions no clear recommendation exist so far [28-30]. In the setting of active infection and contamination, abdominal wall reconstruction is associated with higher rates of hernia than clean wounds, but the best solution for these cases is still debatable [31]. Compared with non-absorbable sutures, the absorbable sutures are expected to reduce the incidence of surgical site infection, although there is no strong evidence to support this effect in the case of gastrointestinal surgery [32].

A recent review on suture techniques and materials for closure of the fascia following laparotomy incisions found that monofilament sutures reduced the risk of incisional hernia when compared with multifilament sutures. On the other hand they found no significant difference in terms of wound infection, wound dehiscence or incisional hernia, whether based on suture absorption, closure method (anatomic layers or mass), or closure technique (continuous or interrupted) [33].

Despite the broad spectrum of polymers available, it is often difficult to meet all the requirements for a medical device at the same time and also remain cost-effectively. In addition, there are inherent problems that arise in the case of polymers, despite their non-toxic behaviour, as there may result some monomer residues from incomplete polymerization and other soluble components. These justify intense polymer testing prior to their transfer into clinical applications [34].

The $p \mathrm{H}$ dependent degradation of a suture should be further studied for various pathologic conditions, since extensive, homogenous clinical data in this field is still lacking.

\section{Conclusions}

Candidate polymers for surgical sutures must comply with the requirements that arise either from their structure or from the physiological destination environment. Tensile strength, degradation degree and stability of the material are the main parameters in the selection of materials for surgical sutures.

The results show that in physiological conditions $(p \mathrm{H}=7.4)$ the investigated surgical sutures with a glycolide component degrade more rapidly, whereas surgical sutures made of polydioxanone degrade and lose tensile strength more rapidly in acidic conditions.

Therefore, surgical sutures with a lower degradation degree and implicitly a higher tensile strength should be used in wounds that require prolonged support in order to avoid wound dehiscence.The integrity of surgical sutures is dependent on the degree of degradation; however, suture techniques and methods of knot formation play also an important role in this matter [35]. 
The interdependency created by the strong bond between $p \mathrm{H}$ and degradation degree should not be overlooked as it can produce an unwanted cascade effect; an increased $p \mathrm{H}$ produces a higher degradation degree and a lower tensile strength that results in a more probable wound dehiscence effect to take place.

\section{References}

1.SCHNEIDER, L.A., KORBER, A., GRABBE, S., DISSEMOND, J., Influence of $p \mathrm{H}$ on woundhealing: A new perspective for wound-therapy?, Arch Dermatol Res, 298, 2007, 413-420.

2.ADANUR, S., Wellington Sears Handbook of Industrial Textiles, 1st ed.; CRC Press-Florida, USA, 1995, 1-832.

3.KIM, J.C., LEE, Y.K., LIM, B.S., RHEE, S.H., YANG, H.C., Comparison of tensile and knot security properties of surgical sutures, J. Mater. Sci.-Mater. Med., 18, 2007, 2363-2369.

4.NOBILE, L., CHECCHI, L., MONACO, G., Experimental analysis of tensile properties of some suturing materials, J. Mater. Sci.-Mater. Med., 8, 1997, 53-56.

5.DENNIS, C., SETHU, S., NAYAK, S., MOHAN, L., MORSI, Y., MANIVASAGAM, G., Suture materials - Current and emerging trends, J. Biomed. Mater. Res. A, 104(6), 2016, 1544-1559.

6.CHU, C.C., Wound Closure Biomaterials and Devices. Chu, C.C., von Fraunhofer, J.A., Greisler, H.P., Eds.; CRC Press-Florida, USA, 2018, 1-416.

7.VAID, R., PASQUINELLI, M.A., KING, M.W., Bioresorbable Polymers for Surgical Suture Applications, in Encyclopedia of Renewable and Sustainable Materials, 1st ed.; Choudhury, I.A., Hashmi, S., Eds., Elsevier Science: Amsterdam, the Netherlands, 2020, 1-17.

8.D'AVILA CARVALHO ERBETTA, C., Synthesis and Characterization of Poly (d,1-Lactide-coGlycolide) Copolymer, J. Biomater. Nanobiotechnol., 3, 2012, 208-225.

9.BLESSY, J., ANNE, G., SREERAJ, G., NANDAKUMAR, K., SABU, T., Polymer suture for simultaneous wound healing and drug delivery - A review, Int. J. Pharm, 524, 2017, 454-466.

10.CHU, C.C., Materials for absorbable and nonabsorbable surgical sutures, in Biotextiles as Medical Implants; King, M.W., Gupta, B.S., Guidoin R., Eds., Woodhead Publishing: Cambridge, UK, 2013, 275-334.

11.CHELLAMANI, K.P., VEERASUBRAMANIAN, D., VIGNESH BALAJI, R.S., Surgical Sutures: An overview, Journal of Academia Industrial Research, 1(12), 2013, 778-782.

12.QIN, Y., Surgical sutures, in Medical Textile Materials, Qin, Y., Ed., Woodhead Publishing: Cambridge, UK, 2016, 123-132.

13.JASSO-GASTINEL, C.F., SOLTERO-MARTÍNEZ, J.F.A., MENDIZÁBAL, E., Introduction: Modifiable Characteristics and Applications, in Modification of Polymer Properties; 1st ed., JassoGastinel, C.F., Kenny, J.M., Eds., Elsevier Science: Amsterdam, The Netherlands, 2017, 1-21.

14.GOPFERICH A., Mechanisms of polymer degradation and erosion, Biomaterials, 17(2), 1996, 103114.

15.PILLAI, C.K.S., SHARMA, C.P., Resorbable polymeric surgical sutures: Chemistry, production, properties, biodegradability, and performance, J. Biomater. Appl., 25(4), 2010, 291-366.

16.TATU, R.F., MARSAVINA, L., VOICONI, T., HURMUZ, M., TATU, C., UNGUREAN, C., ROSU, S., Reinforcement of Tibial Fixation in Anterior Cruciate Ligament Reconstruction Using a Polyester Multi Stranded Long Chain Polyethylene Core Suture Material, Mater. Plast., 51(4), 2014, 460-462.

17.PIRVUT, M.V., GRIGORE, N., MIHAI, I., PRIPOREANU, A.T., RACHERIU, M., CRETU, D., TEODORU, A., SABAU, D., MITARIU, L., RANGA, R., MANEA, M.M., HASEGAN, A., Comparative Study Between Polydioxanone Unidirectional Barbed Suture and Absorbable Polyglactin Running Suture in Partial Nephrectomy, Mater. Plast., 55(1), 2018, 82-84.

18.MAFTEI, G.A., MARTU, C.M., POPA, C., GELETU, G., DANILA, V., JELIHOVSCHI, I., FOIA, L., The Biomechanical Properties of Suture Materials and Their Relationship to Bacterial Adherence, Mater. Plast., 56(4), 2019, 980-985.

19.BUSSE, B., Suturing Techniques for Wound Closure, in Wound Management in Urgent Care, 
Springer International Publishing: New York, USA, 2016, 1-81.

20.FREUDENBERG, S., REWERK, S., KAESS, M., WEISS, C., DORN-BEINECKE, A., POST, S., Biodegradation of absorbable sutures in body fluids and pH buffers, Eur. Surg. Res., 36(6), 2004, 376385.

21.CHU, C.C., The effect of $p \mathrm{H}$ on the in vitro degradation of poly(glycolide lactide) copolymer absorbable sutures, Journal of Biomedical Materials Research, 16, 1982, 117-124.

22.FREUDENBERG, S., REWERK, S., KAESS, M., WEISS, C., DORN-BEINECKE, A., POST, S., Biodegradation of Absorbable Sutures in Body Fluids and pH Buffers, Eur. Surg. Res., 36, 2004, 376385.

23.IM, J.N., KIM, J.K., KIM, H.K., IN, C.H., LEE, K.Y., PARK, W.H., In vitro and in vivo degradation behaviors of synthetic absorbable bicomponent monofilament suture prepared with poly(p-dioxanone) and its copolymer, Polymer Degradation and Stability, 92, 2007, 667-674.

24.PATRICIA SAILEMA-PALATE, G., VIDAURRE, A., CAMPILLO-FERNANDEZ, A.J., CASTILLA-CORTAZAR, I., A comparative study on Poly( $\varepsilon$-caprolactone) film degradation at extreme $p \mathrm{H}$ values, Polymer Degradation and Stability, 130, 2016, 118-125.

25.SCHADE, H., MARCHIONINI, A., Der Säuremantel der Haut (Nach Gaskettenmessungen), Klin. Wochenschr., 7(1), 1928, 12-14.

26.ONO, S., IMAI, R., IDA, Y., SHIBATA, D., KOMIYA, T., MATSUMURA, H., Increased wound $p \mathrm{H}$ as an indicator of local wound infection in second degree burns, Burns, 41(4), 2015, 820-824.

27.MASINI, B.D., STINNER, D.J., WATERMAN, S.M., WENKE, J.C., Bacterial adherence to suture materials, J. Surg. Educ., 68(2), 2011, 101-104.

28.DIENER, M.K., VOSS, S., JENSEN, K., BÜCHLER, M.W., SEILER, C.M., Elective midline laparotomy closure: The INLINE systematic review and meta-analysis, Ann. Surg., 251(5), 2010, 843856.

29.SAVlOVSCHI, C., BRANESCU, C., SERBAN, D., TUDOR, C., GAVAN, C., SHANABLI, A., COMANDASU, M., VASILESCU, L., BORCAN, R., DUMITRESCU, D., SANDOLACHE, B., SAJN, M., GRADINARU, S., MUNTEANU, R., KRAFT, A., OPRESCU, S., Amyand's Hernia - A Clinical Case, Chirurgia, 105(3), 2010, 409-414.

30.DUMITRESCU, D., SAVLOVSCHI, C., BORCAN, R., PANTU, H., SERBAN, D., GRADINARU, S., SMARANDACHE, G., TROTEA, T., BRANESCU, C., MUSAT, L., COMANDASU, M., PRIBOI, M., BALDIR, M., SANDOLACHE, B., OPRESCU, S., Clinical case - Voluminous Diaphragmatic Hernia - Surgically Acute Abdomen: Diagnostic and Therapeutical Challenges, Chirurgia, 106(5), 2011, 657-660.

31.HODGKINSON, J.D., MAEDA, Y., LEO, C.A., WARUSAVITARNE, J., VAIZEY, C.J., Complex abdominal wall reconstruction in the setting of active infection and contamination: a systematic review of hernia and fistula recurrence rates, Color. Dis., 19(4), 2017, 319-330.

32.MAEHARA, Y., et al., Impact of intra-abdominal absorbable sutures on surgical site infection in gastrointestinal and hepato-biliary-pancreatic surgery: results of a multicenter, randomized, prospective, phase II clinical trial, Surgery Today, 47(9), 2017, 1060-1071.

33.PATEL, S.V., PASKAR, D.D., NELSON, R.L., VEDULA S.S., STEELE, S.R., Closure methods for laparotomy incisions for preventing incisional hernias and other wound complications, Cochrane Database Syst Rev, 11(11):CD005661, 2017.

34.JENKE, D., Evaluation of the chemical compatibility of plastic contact materials and pharmaceutical products; safety considerations related to extractables and leachable, J. Pharm. Sci, 96(10), 2007, 25662581.

35.KOMATSU, F., MORI, R., UCHIO, Y., Optimum surgical suture material and methods to obtain high tensile strength at knots: Problems of conventional knots and the reinforcement effect of adhesive agent, J. Orthop. Sci., 11, 2006, 70-74.

$\overline{\text { Manuscript received: } 2.07 .2020}$ 